\title{
A EDUCAÇÃO SALESIANA E A MARCA DA CIVILIZAÇÃO OCIDENTAL NO COMPORTAMENTO DO INDÍGENA DE YAIA POEWANO SÉCULO XX
}

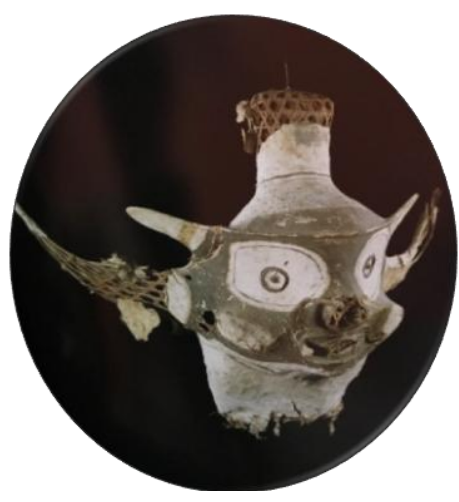

JoscivalV asconcelos Reis1

Gláucio Campos Gomes de Matos2

Odenei de Soura Ribeiro3

\begin{abstract}
Resumo
Este artigo tem o objetivo abordar o processo civilizatório ocidental (sustentado e difundido) incrementado pelos salesianos aos povos indígenas de Yaia Poewa. A concepção de 'civilização' chegou à essa região com o não índio. Nesse longo período de contato com os povos indígenas se constata mudanças no modus vivendis indígena da região. Com avançar do contato e o processo de integração em curso, os indígenas de Yaia Poewa incorporaram transformações que estão presentes em suas realidades socioculturais.O enfoque é qualitativo, com pesquisa bibliográfica e ênfase na teoria do processo civilizador de Norbert Elias, a qual contribui para pensar as mudanças socioculturais ocorridas em Yaia Poewa, incrementadas pela Missão Salesiana Arcanjo São Miguel como instituição de modelação do comportamento do indígena nessa região. A experiência de campo, do eu Tukano, fruto dessas mudanças, contribui para dialogar com a teoria.
\end{abstract}

Palavras-chave: Processo civilizador. Psicogênese. Povos indígenas.

\footnotetext{
${ }^{1}$ Mestrando do Curso de Pós-Graduação em Sociedade e Cultura na Amazônia da Universidade Federal do Amazonas (PPGSCA/UFAM). Bolsista do Programa de Bolsas de Pós-Graduação voltado para o Interior do Estado do Amazonas da Fundação de Amparo à Pesquisa do Estado do Amazonas (PROINT-FAPEAM). E-mail: joscivaltukano@yahoo.com.br.

${ }^{2}$ Professor da UFAM. Professor do Programa de Pós-Graduação Sociedade e Cultura na Amazônia (PPGSCA/UFAM). E-mail: glauciocampos@bol.com.br.

${ }^{3}$ Professor do Programa de Pós-Graduação em Sociedade e Cultura na Amazôniae do Programa de Pós-Graduação em Sociologia (PPGSCA/PPGS/UFAM). E-mail: ribeiroode@hotmail.com.
} 


\section{Resumen}

Este artículo pretende abordar el proceso de la civilización occidental se incrementa en los Salesianos a los pueblos indígenas de Yaia Poewa. El concepto de "civilización" llegó a esta región con los no indios. En este largo período de contacto con los pueblos indígenas observa cambios en el modus vivendis indígena de la región. En anticipación del contacto y el proceso de integración en curso, YaiaPoewa de los cambios incorporados indígenas que están presentes en sus realidades socio-culturales. El enfoque es cualitativo, con la investigación bibliográfica y énfasis en la teoría del proceso de civilización de NorbertElias, que ayuda a pensar en los cambios socioculturales en YaiaPoewa, incrementados por la Misión Salesiana San Miguel como institución de modelización del comportamiento indígena en esta región. La experiencia de campo, del yo Tukano, el resultado de estos cambios, que contribuye al diálogo con la teoría.

Palavras-claves: Proceso de civilización. Psicogénesi. Pueblos indígenas.

\section{INTRODUÇÃO}

O presente artigo tem como temática central compreender mudanças de comportamento de indígenas de Yaia Poewano do Alto Rio Negro/AM, no Séc. XX a partir da introdução da educação Salesiana na região, que impõe uma educação aos moldes ocidentais, negando a educação indígena milenar.

Para essa reflexão, nos apropriamos do conceito de psicogênese discutido por Norbert Elias em sua teoria, apresentada nos livros O Processo Civilizador, volume 1 e 2 . Para o autor podemos entender que o termo psicogênese vai se relacionar as mudanças no comportamento dos indivíduos no longo percurso do desenvolvimento da sociedade. Esse longo processo de desenvolvimento se constata alterações no aparelho psíquico humano.

Nas obras citadas, Elias revela o cotidiano, as atitudes em relação ao corpo, os costumes, o controle sobre as ações corporais, as maneiras de comer, amar, as regras de etiquetas, a formas de como se vestir, entre outros assuntos que evidenciam a psicogênese. 
Amparado na teoria eliasiana, buscamos compreender a psicogênese indígena a partir da ação da Missão Salesiana Arcanjo São Miguel que teve uma contribuição significativa na modelação do comportamento e das estruturas de personalidades (psicogênese) do ser indígena de Yaia Poewano século XX.

\section{A PSICOGÊNESE EM NORBERT ELIAS}

A psicogênese é explicitada por Elias no livro O Processo Civilizador e diz respeito às transformações do comportamento humano e das estruturas de personalidade dos indivíduos.

A teoria dos processos civilizadores proposta por Elias, baseia-se na defesa de que, toda e qualquer transformação ocorrida na estrutura da personalidade do ser individual (psicogênese), produz uma serie de transformações na estrutura social em que o indivíduo está inserido, isso nos leva ao entendimento de que:

Embora os seres humanos não sejam civilizados por natureza, possuem por natureza uma disposição que torna possível, sob determinadas condições, uma civilização, portanto uma auto-regulação individual de impulsos do comportamento momentâneo, condicionado por afetos e pulsões, ou desvio desses impulsos de seus fins primários fins secundários, e eventualmente também sua configuração sublimada. [...] Dado que os seres humanos, diferentemente de muitos outros seres vivos sociais, não possuem uma regulação nativa dos afetos e pulsões, eles não podem prescindir da mobilização de sua disposição natural rumo à auto-regulação mediante o aprendizado social dos controles dos afetos e pulsões, no sentido de um modelo de civilização especifico da sociedade, a fim de que possam conviver consigo mesmos e com os outros seres humanos. O processo universal de civilização individual pertence tanto às condições de individualização do ser humano singular com às condições da vida social em comum dos seres humanos (ELIAS, 2002, p. 21). 
A temática da psicogênese no contexto dos processos de civilizadores trata de entender a formação e as alterações da estrutura psicológica individual, ou processo de civilização individual, o qual, por sua vez, é fruto de um processo civilizador social operante durante muitos séculos, a que todos os indivíduos são automaticamente submetidos desde a mais tenra infância, em maior ou menor grau ou maior ou menor sucesso ELIAS, 1994, p. 15).

\begin{abstract}
Atualmente, o círculo de preceitos e normas é traçado com tanta nitidez em volta das pessoas, a censura e pressão da vida social que lhes modela os hábitos são tão fortes, que os jovens têm apenas uma alternativa: submeter-se ao padrão de comportamento exigido pela sociedade, ou ser excluído da vida num "ambiente decente". A criança que não atinge o nível de controle das emoções exigido pela sociedade é considerada como "doente, "anormal", "criminosa", ou simplesmente "insuportável" do ponto de vista de uma determinada casta ou classe e, em consequência, excluída da vida (ELIAS, 1994, p. 146).
\end{abstract}

Numa sociedade civilizada há de entender que [...] nenhum ser humano chega civilizado ao mundo e que o processo civilizador individual que ele obrigatoriamente sofre é um função do processo civilizador social (ELIAS, 1994, p. 15). É nesse sentido que aponta a semelhança entre a estrutura dos sentimentos e consciência da criança com as das pessoas "incivis", e, portanto, pressionada a se modelar conforme os padrões de comportamento exigidos pela sociedade civilizada.

Segundo Elias (1993) com a formação do Estado, houve uma maior pacificação interna das sociedades e as pessoas foram obrigadas a conviverem pacificamente umas com as outras, agindo de uma determinada maneira a buscar uma vida menos conflituosa. O controle externo - controle social - se tornou em autocontrole a partir do código de conduta e o padrão de comportamento foi incrementado.

De acordo do Elias, 
O estudo desses mecanismos de integração, porém, também é relevante, de modo mais geral, para a compreensão do processo civilizador. Só se percebermos a força irresistível com a qual uma estrutura social determinada, uma forma particular de entrelaçamento social, orienta-se, impelida por suas tensões, para uma mudança específica e, assim, para outras formas de entrelaçamento, é que poderemos compreender como essas mudanças surgem na mentalidade humana, na modelação do maleável aparato psicológico, como se pode observar repetidas vezes na história humana, desde os tempos mais remotos até o presente (Elias, 1993, p. 195).

Dessa forma, é possível, então, entender que a especificidade da teoria de Elias está na indissociabilidade entre o desenvolvimento das estruturas de personalidade e das estruturas sociais, ou seja, não se pode entender as transformações sofridas pelas sociedades separadamente das alterações ocorridas nas estruturas de personalidade dos indivíduos que as formam.

\section{OS MISSIONÁRIOS SALESIANOS NO ALTO RIO NEGRO}

A Pia Sociedade de São Francisco de Sales, também conhecida como Congregação Salesiana ou Salesianos é uma congregação da Igreja Católica Apostólica Romana fundada em 18 de dezembro de 1859 por Dom Bosco (João Melchior Bosco), em Turim, Itália. Dom Bosco foi sacerdote diocesano e educador. Desenvolveu a educação infanto-juvenil e o ensino profissional e criador do Sistema Preventivo em Educação. Devido a isso a congregação especializou-se em educar jovens operários rurais e dar assistência aos enfermos. Educavam os jovens utilizando o paradigma de civilidade urbana moderna, de formação integral e, desta forma, integrá-los à sociedade italiana. Foi com essa ideologia que a congregação salesiana chegou ao Brasil em 1883 (AZZI, 1983). 
A ação missionária salesiana junto a populações indígenas no Brasil iniciou em Cuiabá, Mato Grosso, em 1893, com os indígenas Bororos. Projetaram escolas agrícolas objetivando reunir os indígenas no intuito de ensiná-lo a desenvolver vários ofícios ligados à terra, modelar o seu corpo e espírito. Esse modelo também seria aplicado nas missões salesianas do Alto Rio Negro, noroeste do Amazonas, onde os missionários tomaram os indígenas da região como crianças desamparadas e consideraram ser uma missão educar esses povos com objetivo de integrálo ao estado nacional. Por isso, a educação escolarizada foi instrumento que serviu para diluir culturas, atendendo aos projetos do sistema liberal implícito na catequização desses povos indígenas. WEIGEL (2000, p. 109) afirma:

É neste sentido, da busca em aprofundar e consolidar entre os indígenas a produção de um estilo de vida e de um imaginário, adequados ao interesse dos grupos sociais dominantes, que o Estado Brasileiro acolhe, respalda e apóia a fundação da escola e de um vasto trabalho missionário no Alto Rio Negro, pelos religiosos salesianos na primeira década do século XX.

Para facilitar a educação dos alunos indígenas, as escolas salesianas gradativamente foram organizadas, instaladas e consolidadas em cinco pontos estratégicos na forma de grandes internatos e/ou centros missionários chamados de "núcleos de civilização" (WEIGEL (2000, p. 113) São Gabriel da Cachoeira, na sede do município, em 1915; Taracuá, no Baixo Rio Uaupés, em 1924; Pari Cachoeira, no Médio Rio Tiquié, em 1938; Iauaretê, no Médio Rio Uaupés, em 1929; Nossa Senhora da Assunção, Baixo Rio Içana, em 1953; Maturacá, no Rio Cauaburis, em 1958; e Marauiá, Rio Marauiá, em 1968. Estas duas últimas junto aos Yanomami. Ao mesmo tempo, foram também fundados escolas, hospitais e igrejas, incentivando nessas localidades um processo intenso de povoamento. 
Paula (2005) afirma que o objetivo principal dos missionários salesianos estava pautado na educação, saúde e catequese. Através destes centros missionários, os salesianos passaram a influenciar os mais diferentes aspectos da vida dos povos indígenas, especialmente daqueles situados próximo às missões.

Nos meados da década de 1920, a atuação salesiana é não só assegurada, mas mantida pelo próprio Estado brasileiro. A partir de 1960, a relação entre duas instituições passou a ser formalizada por meio de convênios e a educação escolarizada passa a ser dirigidas pela Congregação Salesiana e pelas irmãs do Instituto das Filhas de Maria Auxiliadora (F.M.A.).

O Instituto das FMA foi fundado no dia 5 de agosto de 1872, em Mornese, na Itália. Dom Bosco ansiava pela criação de um instituto feminino que pudesse realizar o trabalho educativo e evangelizador que já era promovido para meninos. Ao conhecer Maria Domingas Mazzarello e o trabalho que ela realizava, enxergou a possibilidade de tornar seu sonho realidade. Madre Mazzarello foi a co-fundadora e primeira diretora do Instituto. No Brasil vieram da Epistolia Santa Catarina do Rio de Janeiro no dia 10 de janeiro de 1923, chegaram na região em 16 de fevereiro de 1923 (AZZI, 1983).

A implantação da obra salesiana na Amazônia, na região do Alto Rio Negro, tinha como objetivo principal, segundo Silva (1977, p. 9) [...] incorporar os pobres silvícolas na civilização brasileira cristã”. Durante quase um século, a ação salesiana teve por objetivo explícito: a aculturação indígenas. Com essa finalidade buscou concentrar essas populações em determinados centros missionários, transformar gradualmente as moradias coletivas em individuais, estabelecer espaços domesticados para manifestação ritual e socializar as crianças indígenas em internatos visando interferir em muitos aspectos da organização sociocultural dos povos indígenas, considerada "incivilizada" e profana pelos missionários 
salesianos provocando esvaziamento das antigas aldeias, perda das tradições e valores culturais. "O incentivo dado ao aluno indígena para permanecer no internato salesiano era em detrimento a essas atividades" (FARIA, 2003, p. 30).

Para Matos (2015), o princípio salesiano da persuasão, formar o bom cidadão e de uma educação assistida, permite compreender o sentido do vigiar e inibir manifestações socioculturais. Para o autor, o processo civilizador desencadeou um comportamento ao molde ocidental. O decoro, ou seja, a decência e a vergonha medeiam, a partir de então, atos e comportamentos culturais. Nesse processo a diferenciação social e a individualização se fazem notar.

\section{MISSÃO SALESIANA EM YAIA POEWA/YAIWI PANI/IAUARETÊ: A PSICOGÊNESE INDÍGENA}

Yaia Poewaou Yawi Panié é um povoado multicultural localizado na fronteira Brasil e Colômbia, às margens do Uaupés, um dos formadores da bacia do Alto Rio Negro, no noroeste amazônico. É um ponto de referência mito-histórico-sociocultural de grande relevância. $\mathrm{Na}$ língua Tukano e Tariana significa Cachoeira das Onças. Devido ao contato com a Língua Geral trazida pelos agentes da expansão colonial e do processo civilizatório no século XIX foi denominada de Iauaretê que significa somente "onça". A Língua Geral foi difundida inicialmente pelos jesuítas e empregada pelos franciscanos na época do estabelecimento das aldeias indígenas no Alto Rio Negro. Yaia Poewa é um dos lugares míticos importante, pois trata da história do mundo e da origem dos diversos grupos indígenas que habitam a região do Uaupés, Papuri e Tiquié.

É uma região distinta demográfica e geograficamente de outras regiões do Brasil. Iauaretê localiza na confluência dos rios Papuri e Uaupés, no noroeste do Estado do Amazonas, no Município de São Gabriel da 
Cachoeira. O Rio Uaupés é o principal tributário do Rio Negro com cerca de $1.375 \mathrm{~km}$ de extensão. Das cabeceiras até o limite Colômbia/Brasil são $845 \mathrm{~km}$. Serve de fronteira com a Colômbia por mais de $188 \mathrm{~km}$; daí até a foz - margem direita do Rio Negro - são mais $342 \mathrm{~km}$ em território brasileiro (CABALZAR \& RICARDO, 2006, p. 06).

É povoada por grupos indígenas de diversas etnias da Família Lingüística Tukano, Aruak e Maku. A primeira família é representada por Tukano, Desano, Tuyuka, Wanano, Kubeo, Waikhana e Arapaso; a segunda por Baniwa e Tariana; e a última por Hupdah. Essa diversidade sociocultural vive de produção de subsistência como roça, coleta de frutos silvestres, caça e pesca. Convivem conforme a sua organização sociocultural. Todas as etnias estão dispostas de acordo com a sua organização sociocultural própria: um sistema hierárquico cosmologicamente justificado. Cada etnia hierarquiza também seus subgrupos, definidos em torno de um descendente ancestral masculino, respeitando o padrão exogâmico e patrilocal dos laços matrimoniais (FERREIRA, 2007).

O grupo Tukano seria constituído por grupos migrantes vindos do oeste - Napo e Putumayo - que passaram a ocupar a bacia do Rio Uaupés. O Aruak teria vindo do norte em sucessivas ondas migratórias que dispersaram no Alto Orinoco e Rio Guainia - na Venezuela - e uma parte do Uaupés. O grupo Maku teria sido formado por uma cultura rudimentar que desconheciam a lavoura, a cerâmica, a arte têxtil e a navegação (NIMUENDAJU, 1982).

Ferreira (2007) salienta que os povos indígenas dessa região, tradicionalmente, vive da caça, pesca, coleta de frutos silvestres e atividades de subsistência na agricultura, a roça. A roça de mandioca faz parte do cotidiano indígena. A mandioca não é o único produto cultivado na roça, pois planta-se também o cará, a abóbora, a melancia, a cana, o milho, a cucura, o ingá, o abiú, o açaí, o cupuaçu e outros. Após décadas de 
introdução de novas técnicas de cultivos pelos não indígenas, a roça continuou a existir como essencial para a sobrevivência da cultura indígena.

Essas sociedades desenvolveram nessa região, a centenas de anos, formas sofisticadas de adaptação ao meio ambiente regional e práticas diversas e complementares de subsistência em ecossistemas tidos como os mais pobres da Amazônia, em virtude da baixa fertilidade de suas terras e pobreza dos rios em peixes. Apropriaram de plantas medicinais, desenvolveram técnicas de cultivo, pesca e de fabricação de utensílios domésticos pertinentes para a utilidade diária e para sua sobrevivência.

Em 1892 Manaus é elevada à categoria de Diocese. A Santa Sé, objetivando a evangelização na Amazônia, criou as Prefeituras Apostólicas e Prelazias, as últimas eram regiões menores, confiando-as às congregações religiosas. Em 06 de novembro de 1888, os Franciscanos deixaram o Rio Negro e a região recebia visitas esporádicas de missionários ligados à Diretoria Geral dos Índios. Em 1907, Dom Frederico Costa, segundo bispo da Diocese de Manaus, viaja no Rio Solimões e Rio Negro, chegando até Iauaretê. Dom Frederico encontrou a população indígena numa situação de miséria, de exploração e escravização, imposta pelos comerciantes e Diretores de Índios. Retornou para Manaus e fez o seu relatório de viagem. Em seguida viajou para Roma, a fim de relatar ao Papa Pio X a realidade da população da Amazônia. O resultado disso foi a criação da Prefeitura Apostólica do Rio Negro, em 19 de outubro de 1910, confiada à Congregação Salesiana em junho de 1914 (PAULA, 2005).

Em 29 de setembro de 1929 foi fundada a Missão Salesiana de Iauaretê, sob o nome de Arcanjo São Miguel. A fundação consistiu na escolha e benção do lugar, seguida pela celebração da Primeira Missa. A partir daí foi necessário e imprescindível utilizar mão-de-obra indígena para realizar aterro, construção da casa dos salesianos com internato para meninos, a casa das freiras com internatos para meninas, da igreja, do hospital e barracões para hospedagem, serraria e olaria. E em 22 de maio de 
1930 chegam as primeiras freiras do Instituto Filhas de Maria Auxiliadora e no mesmo período o internato começou a funcionar (FERREIRA, 2007).

No internato os Missionário Salesianos e as Filhas de Maria Auxiliadora ofereciam conforme o gênero o ensino primário e elementar, cursos regulares de agricultura prática, aprendizagem profissional em oficinas de carpintaria, marcenaria, alfaiataria, ferraria e mecânica elementar, olaria para os menores e cursos regulares de ensino doméstico e profissional para as meninas como costura, corte, bordado, chapéus e confecções, lavanderia e engomagem e princípios de higiene e enfermagem. Associado a educação, a assistência espiritual e o ensino religioso era uma das atividades desenvolvidas pelos missionários, assim, os preceitos do catolicismo iam aos poucos se alicerçando na mente dos alunos que posteriormente seriam os divulgadores desse programa de evangelização.

A civilização inscreve-se no campo das ações e decisões humanas, comportando um olhar sobre os indivíduos como construtores e construídos pela sociedade ocidental, ou seja, é possível afirmar que a civilização comporta um projeto de ordenação do mundo, quer no presente, quer para o futuro, em que, no nosso entendimento, a infância tem um papel fundamental na construção da sociedade cada vez mais civilizada, à medida que "a vida delas tem que ser rapidamente submetida ao controle rigoroso e à modelagem específica que dão a nossa sociedade seu caráter e que se formou na lentidão dos séculos" (ELIAS, 1994, p. 145).

Distantes do seu grupo sociocultural, pais e família, crianças, moças e rapazes levados para o internato aprendiam a língua, a vida, os costumes e a cultura dos não indígenas, a cultura da sociedade ocidental. Eram obrigados a esquecer os seus atributos socioculturais, pois podiam ser severamente castigadas caso praticassem, pois vigorava na época a política indigenista do Estado Brasileiro na "integração dos índios à comunidade nacional". Os missionários, todos oriundos da cultura ocidental foram formados no espírito dessa ideologia, pois difamaram a cultura indígena 
local, julgando-a como sendo coisa do mal, do demônio, em outras palavras, segundo Matos (2015), o princípio da alteridade foi sensivelmente negado quando da imposição do modelo da civilização cidental.

Os alunos indígenas eram preparados para formação cristã, intelectual e moral através da imposição dos regimentos propostos pelos salesianos baseados na prática catequética de constante oração e serviço a Deus objetivando a salvação das almas. Isso consistia em destruir todos os elementos e símbolos étnicos e socioculturais dos povos indígenas da região. Antes de tudo era necessário batizar as crianças e posteriormente levá-las de suas casas, família e do seu convívio sociocultural para serem educadas rigidamente no internato e tornar "civilizadas".

Os missionários tinham convicção de que só mudariam os indígenas de maneira eficaz com ênfase ao sistema educacional “civilizador" voltado para as crianças e jovens indígenas. A igreja tinha o domínio absoluto sobre a escola e as práticas pedagógicas salesianas. Por isso, como educadores proibiam e perseguiam as línguas indígenas, a organização sociocultural de cada povo indígena e como missionário da Igreja Católica Apostólica Romana proibiam e perseguia os pajés, os rituais, as cerimônias e as danças. Num olhar em retrospectiva, Matos (2015) de forma incisiva, sustenta que o Amazonas viveu um surto descivilizatório no espoliar, escravizar, matar e eliminar grupos indígenas.

Matos (idem) ao direcionar sua atenção aos indígenas suscita que o processo de integração desencadeou um processo de desintegração interno. A tradição cultural guerreira de embate físico foi suavizado pelo diálogo. O tempo cronometrado passo a fazer parte do cotidiano de grupos étnicos. Nesse processo grupos étnicos deixaram de falar sua língua; ocorreu a informalização de costumes, entre eles a memória não é a única referência do conhecimento passado pela oralidade, pois a escrita já foi absorvida e cada vez mais sendo incrementada; o pajé perdeu sua função para medicina dos não índios e seu Deus, agora é Jeová. E sobre esse 
último, podemos ver que a [...] crença na onipresença punitiva ou premiadora de Deus teve sim um efeito "civilizador" ou de controle das emoções (ELIAS, 1994, p. 198).

\begin{tabular}{|c|c|c|c|}
\hline \multicolumn{4}{|c|}{ HORÁRIO DO INTERNATO } \\
\hline \multicolumn{2}{|r|}{ DIAS ÚTEIS } & \multicolumn{2}{|c|}{ DIAS SANTOS } \\
\hline Horário & Atividade & Horário & Atividade \\
\hline 5:00 & Levantar do salesianos & $5: 15$ & Levantar dos salesianos \\
\hline $5: 30$ & Levantar dos alunos & $5: 45$ & Levantar dos alunos \\
\hline $6: 00$ & Missa/mingau/recreio & $6: 15$ & Missa/oração/mingau/recreio \\
\hline $7: 30$ & Trabalho & $7: 30$ & Estudo \\
\hline $9: 15$ & Merenda/recreio & $8: 00$ & Missa/recreio/merenda \\
\hline $9: 35$ & Canto/estudo & $10: 15$ & Aula/civilidade/cerimônias \\
\hline 10:05 & Aula & $10: 45$ & Recreio \\
\hline $10: 50$ & Recreio & $11: 00$ & Almoço/passeio/merenda \\
\hline $11: 00$ & Almoço/recreio & $16: 00$ & Oração/catecismo/bênção \\
\hline $12: 15$ & Banda & $17: 00$ & Jantar/recreio \\
\hline $12: 45$ & Ginástica & 19:00 & Votos/repouso \\
\hline $13: 15$ & Aula & & \\
\hline $14: 45$ & Merenda/recreio & & \\
\hline $15: 00$ & Trabalho & & \\
\hline $16: 30$ & Banho & & \\
\hline $17: 30$ & Jantar/recreio & & \\
\hline $18: 45$ & Catecismo/oração/repouso & & \\
\hline
\end{tabular}

Tabela 1: Horários das Atividades do Internato Salesiano

Fonte: Regimento do Internato (Missão Salesiana, 1933).

Nesse processo, houve o desenvolvimento do conjunto das normas, censuras, proibições, costumes, tensões e emoções que aos poucos foi transformando o comportamento e as estruturas de personalidades de indígenas.

Na educação salesiana em Yaia Poewaou Yawi Panié os indígenas que ficavam internos deviam seguir um rigoroso sistema de horário de trabalho, de estudo, de recreio, de merenda, de almoço, de cerimoniais e celebrações católicas. Sobre o sistema de horário FERRREIRA (2007) demonstra:

Para Elias (1998), o tempo, uma construção simbólica, passou a agir de fora para dentro de forma coercitiva e passou a fazer parte da 
estrutura de nossa personalidade. Símbolo de uma regulação social e uma marca do processo civilizador, o tempo cronometrado foi imposto e rompeu com as orientações do tempo natural. A associação do tempo cronometrado à prática e o cumprimento de tarefas e atividades biológicas moldaram o comportamento para atender preceitos civilizacionais, em outras palavras, tudo aquilo que seria da cultura ameríndia e que causasse estranheza ao colonizador deveria ser extirpado. As imposições sociais sobre grupos étnicos foram, por vezes, dolorosas e com o passar dos anos o indígena incorporou usos e costumes da sociedade ocidental.

\section{CONSIDERAÇÕES FINAIS}

A teoria eliasiana nos permite compreender a forma como as transformações da sociedade ocidental ocorreu ao longo do seu desenvolvimento. O homem natural foi suplantado por um comportamento civilizacional, que o colonizador incrementou no Amazonas.

Tais comportamentos são marcas das transformações que aconteceram e acontecem na nas realidades socioculturais dos povos indígenas de Yaia Poewa, destacando a Missão Salesiana como umas das agências de modelação do comportamento indígena no século XX.

\section{Referências}

AZZI, Riolando. Os salesianos no Brasil: à luz da bistória. São Paulo: Ed. Salesiana Dom Bosco, 1983.

CABALZAR, Aloisio e RICARDO, Carlos Alberto. Povos Indígenas do Rio Negro, uma introdução à diversidade socioambiental do noroeste da Amazônia Brasileira. São Gabriel da Cachoeira. FOIRN. ISA, 2006.

ELIAS, Norbert. Escritos e Ensaios I: Estado, Processo, Opinião Pública. Rio de Janeiro: Jorge Zahar, 2002. 
, Norbert. O processo civilizador: Formação do Estado e Civilização. Rio de Janeiro: Jorge Zahar Ed., 1993.

Norbert. O processo civilizador. Uma história de costumes. Rio de Janeiro: Jorge Zahar, 1994.

, Norbert. Sobre o tempo. Rio de Janeiro: Jorge Zahar, 1998.

FARIA, Ivani Ferreira de. Territorialidades Indígenas do Alto Rio Negro.Manaus: Editora da Universidade Federal do Amazonas - UFAM, 2003.

FERREIRA, Geraldo Veloso. Educação Escolar Indígena:As Práticas Culturais Indígenas na Ação Pedagógica da Escola Estadual Indígena São Miguel Ianaretê $(A M)$. Dissertação de Mestrado. Pontifícia Universidade Católica de São Paulo, São Paulo: PUC, 2007.

PAULA, Nilton Cezar de. A Ação Missionária do Catolicismo e os Povos Indígenas do Rio Negro: Evangelização X Autodeterminação e sobrevivência cultural. Dissertação de Mestrado. Universidade Federal de Pernambuco, Recife: UFPE, 205.

MATOS, Gláucio Campos Gomes de. Ethos e Figurações na Hinterlândia Amąônica. Manaus: Valer/Fapeam, 2015.

NIMUENDAJÚ, Curt. Textos Indigenistas. São Paulo: Editora Loyola, 1982.

SILVA, AlcionilioBrüzzi Alves da. Uma explicação. In: A civilização indígena do uaupés: observações antropológicas, etnográficas e sociológicas. 2. ed. Roma: LibreriaAteneo Salesiano: 1977.

WEIGEL, Valéria Augusta Cerqueira de Medeiros. Escolas de branco em malocas de indio. Manaus: Editora da Universidade Federal do Amazonas, 2000 . 